\title{
Predicting Soil-Water Characteristic Curves of Clayey Sand Soils Using Area Computation
}

\author{
M. A. Dafalla $\mathbb{D}^{1},{ }^{1}$ A. M. Al-Mahbashi, ${ }^{1}$ A. Almajed, ${ }^{2}$ and M. Al-Shamrani ${ }^{1}$ \\ ${ }^{1}$ Bughshan Research Chair in Expansive Soils, Civil Engineering, King Saud University, Riyadh, 11421, Saudi Arabia \\ ${ }^{2}$ Civil Engineering Department, College of Engineering, King Saud University, Riyadh 11421, Saudi Arabia \\ Correspondence should be addressed to M. A. Dafalla; mdafalla@ksu.edu.sa
}

Received 26 November 2019; Revised 5 May 2020; Accepted 15 May 2020; Published 3 June 2020

Academic Editor: Akemi Gálvez

Copyright (C) 2020 M. A. Dafalla et al. This is an open access article distributed under the Creative Commons Attribution License, which permits unrestricted use, distribution, and reproduction in any medium, provided the original work is properly cited.

The soil-water characteristic curves (SWCCs) for soils are important for geotechnical engineers in the prediction of clay behavior in case of partially saturated conditions. In the wastewater and waste containment industry, variable clay content is considered. It is not practical to run a time-consuming test several times to obtain the soil-water characteristic curves for every proportion. This study is aimed at introducing a practical procedure to predict the response of clay of known mineralogy and geological setting when clay content within a liner is variable. Fitting curves were performed using Fredlund and Xing's (1994) equations. The general trends were established for selected clay of known high content of smectite minerals. Obtained curves were examined, and areas under the suction curve were integrated from the starting point to the inflection point for clay-sand material with $5 \%, 10 \%$, $15 \%, 30 \%, 60 \%$, and $100 \%$ clay content. This area can be used to estimate the profile of the SWCC for higher or lower clay content based on an area factor determined for a specific clay type or clay of known mineralogy. Other clay of similar nature, but not typical mineralogy, were compared in order to observe and validate the use of the area method in predicting the SWCC for similar soils.

\section{Introduction}

The engineering properties of partially saturated soils are now easily predicted using mathematical models designed for unsaturated soil mechanics; these models are popular and accepted worldwide [1, 2]. Soil-water characteristic curves (SWCCs) are used to indirectly predict hydraulic conductivity and shear strength parameters through a hydraulic conductivity function and a shear strength function, respectively [3-6].

The concept of these predictions started as early as the 1960s when Brooks and Corey [7] studied the hydraulic properties of porous media and introduced a framework for the behavior of partially saturated soils.

Models describing the state of suction at variable water content have been introduced by many researchers $[1,8-10]$. Common reference terms related to the SWCC include the air-entry value (AEV), residual suction (Rs), and residual water content (Wr). The suction measured at the point when the air starts to take up a space within the water soil system is referred to as the air-entry value. When the suction pressure increases, the water content is reduced until a level where all further reductions in water content are small compared to the applied suction. The suction and water content at this point are both considered residual values. Geometric or volumetric water content plotted against soil suction is generally used to establish the SWCC. Models of flow of water through unsaturated soils require information related to the SWCC. There are several factors that can influence the SWCC profile. These include and are not limited to particle and pore size distribution, soil chemistry and fabric, soil density, and soil temperature [11-13].

Montanez [14] studied the suction and volume changes for compacted mixtures of sand and bentonite. Agus and Schanz [15] studied the wetting and drying suction characteristic curves of bentonite sand. Pei-yong and Qing [16] covered the SWCC and water retention of bentonite sand mixtures. These three studies confirmed the increase of 
retention capacity with the increase in clay content. AlMahbashi et al. [17-19] conducted several works on the soilwater characteristics for selected soils at different conditions.

Zhou et al. [13] presented a model to predict the SWCC for different initial density conditions by introducing a new parameter calibrated using experimental results.

Most of the studies considered Fredlund and Xing's [1] model to fit the laboratory data of moisture and soil suction. The construction of a single SWCC is a time-consuming process and may involve several techniques if the entire suction range is to be studied. As sand bentonite mixtures are frequently used for liners and hydraulic barriers, the need for a quick and yet reliable procedure is of interest to engineers. This work is aimed at utilizing results collected from the experimental work for a wide range of suction and moisture content in order to establish a prediction chart for similar soils with variable clay content.

\section{Material and Characteristics}

2.1. Material Used. The highly plastic and highly expansive clay of Al-Qatif which has been proposed by different researchers for use in liner and waste barrier applications was selected for this study. The fine sand material used in many construction activities was obtained from Riyadh, Saudi Arabia. This material is poorly graded in general, with occasional silt components. The coefficient of uniformity and the coefficient of curvature were measured as 1.737 and 1.078 , respectively. The specific gravity of the sand used is 2.66. The specific gravity, liquid limit, plastic limit, and plasticity index for the bentonite material used are given in Table 1.

The Eastern Province of Saudi Arabia is known for expansive clay reported in Al-Qatif region. Al-Qatif region is a historic, oasis located along the western coast of the Arabian Gulf in the Eastern Province of Saudi Arabia $\left(26^{\circ}\right.$ $56^{\prime} 0^{\prime \prime} \mathrm{N}, 50^{\circ} 1^{\prime} 0^{\prime \prime} \mathrm{E}$ ). This clay is highly plastic and classified as $\mathrm{CH}$ in accordance with [20]. According to Azam [21], this clay is of high smectite content. All natural clay used in this study were obtained from Al-Qatif using a hydraulic excavator for near-surface material. The depth of samples was between $0.5 \mathrm{~m}$ and $3 \mathrm{~m}$. Detailed geotechnical characterization was carried out in King Saud University laboratories.

Other materials used included commercial bentonite HY OCMA obtained by a local supplier. The index properties of HY OCMA bentonite are given in Table 2 .

2.2. Compaction Curves of Mixtures. The SWCCs were investigated for a selected range of clay content. The samples were normally prepared at the maximum dry density and optimum moisture content. The Al-Qatif sand mixtures with clay contents spanning from $5 \%$ to $100 \%$ pure clay were prepared. Other mixtures including bentonite (HY OCMA) and Al-Qatif clay were also investigated for the purpose of prediction and validation of the prediction model. The compaction tests were carried out in accordance with the standard Proctor compaction method, ASTM D698-method A [22]. For the sand-Al-Qatif clay mixtures,
Table 1: Properties of bentonite.

\begin{tabular}{lc}
\hline Property & Value \\
\hline Specific gravity, GS & $2.6-2.7$ \\
Liquid limit, LL (\%) & 480 \\
Plastic limit, PL (\%) & 49.6 \\
Plasticity index, PI (\%) & 430 \\
\hline
\end{tabular}

TABle 2: Properties of Al-Qatif clay.

\begin{tabular}{lc}
\hline Property & Value \\
\hline Specific gravity, GS & $2.71-2.75$ \\
Liquid limit, LL (\%) & $137-140$ \\
Plastic limit, PL (\%) & $45-60$ \\
Plasticity index, PI (\%) & $95-99$ \\
Unified soil classification system & $\mathrm{CH}$ \\
\hline
\end{tabular}

the range of clay content investigated included $0 \%, 5 \%, 10 \%$, $15 \%, 30 \%$, and $60 \%$ by dry weight of sand. For the sandcommercial bentonite mixtures, the range of clay content studied included was $15 \%$, but the proportion of natural clay (Al-Qatif) and bentonite was varied from one-third to twothirds. All samples of mixtures were prepared with different water contents ranging from $5 \%$ to $36 \%$. Distilled water was added to the mixtures to obtain the desired water contents.

The mixtures were allowed to hydrate for 24 hours, while placed in plastic bags prior to compaction. A $5.5 \mathrm{lb}$ hammer was used to compact the mixtures into a $100 \mathrm{~mm}$ mold (inside diameter) with a height of $101.3 \mathrm{~mm}$. Three layers of mixtures were placed and compacted in order to ensure uniform compaction. The process of establishing compaction curves includes plotting the weight of the soil in the mold after compaction and the associated water content. Three typical curves for $15 \%, 30 \%$, and $60 \%$ are presented in Figure 1 . The general profile for the maximum dry density and optimum moisture content is presented in Table 3.

The moisture-density relationship of clay-sand mixtures was investigated for variable clay content. Figure 1 presents an example of a dry density-moisture profile as obtained for a clay-sand mixture with $15 \%$ clay content. The maximum dry density was reported as $18.0 \mathrm{kN} / \mathrm{m}^{3}$, and the optimum moisture content was found to be $15 \%$. The values of the maximum dry density are presented in Table 3.

When replacing Al-Qatif clay with one-third or twothirds volume as bentonite, the variation in the maximum dry density and optimum moisture content is small and not significant.

\section{Experimental Work and Procedures}

3.1. General. Two main approaches were followed to test AlQatif clay-sand mixtures for soil-water characteristics. The first procedure involved axis translation technique, while the second utilized the filter paper technique. These methods depend on the suction level, and the first method is more reliable for suction values between $10 \mathrm{kPa}$ and $1,500 \mathrm{kPa}$ utilizing a pressure plate in accordance with ASTM D6836 [23], while filter paper techniques are used for measuring matric suction greater than $1,500 \mathrm{kPa}$. 


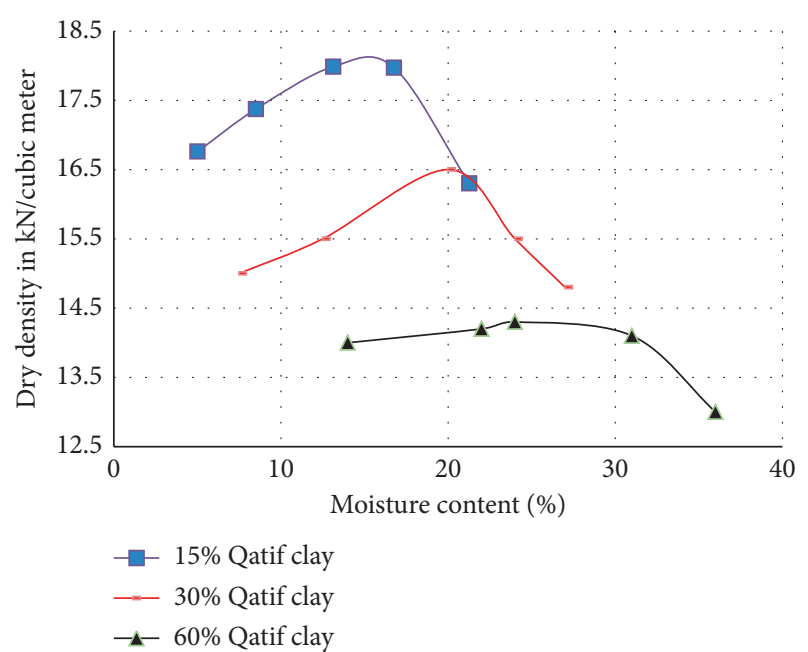

Figure 1: Dry density-moisture relationship (15\%, 30\%, and 60\% Al-Qatif clay-sand mixture).

3.2. Pressure Plate. The initial molding for the clay-sand mixtures was prepared at the maximum dry density (MDD) and optimum moisture content (OMC). The specimens were extracted in two inch diameter rings and then inundated in distilled water for at least 24 hours. Extra time was allowed to ensure saturation. A $7 \mathrm{kPa}$ stress was applied to the specimens during the saturation period.

Upon removal of the specimen from the inundation cell, it was observed that a saturated surface dry condition was achieved. This was accomplished by using a mop or paper towel. High-air-entry ceramic disks of 5 bars to 15 bars are also needed to be saturated in water overnight.

Assuring good contact between saturated soil specimens and the saturated high-air-entry ceramic disk, the whole assembly is placed in the pressure chamber. The chamber is then tightly closed using screw bolts (Figure 2). Outer air pressure source was used to apply suction in increments starting from $10 \mathrm{kPa}$ and increasing to $50 \mathrm{kPa}$. Further increments included 100, 200, 400, 800, and $1,400 \mathrm{kPa}$. A flow-out tube leading to a graduated cylinder was attached. The time allowed for each increment was in the range of two to three days until equilibrium was achieved, i.e., when no more water was expelled from the specimen. The device cell is dismantled following equilibrium, and moisture content for the specimen was calculated using gravimetric methods. This enabled computing the amount of water loss at each suction level and the final water content.

3.3. Filter Paper Technique (FPT). For suction in excess of $1,500 \mathrm{kPa}$, the axis translation procedure would not be suitable due to the ceramic disk suction level tolerance. FPT was used to cover the zone in excess of $1,500 \mathrm{kPa}$ to evaluate the trend of the SWCC over a high suction range (up to $100 \mathrm{MPa}$ ). The measurement of matric suction is not direct, and it requires samples of predetermined water content. A series of compacted disk specimens need to be conditioned to variable water content. This can be attained by drying or wetting of compacted specimens to achieve the required water content.

In order to obtain target water content, drying or wetting was performed in a controlled manner simulating natural conditions. Up to five days were allowed for drying to achieve specific moisture content. Wetting is achieved by placing the samples in a humid environment. After target moisture is achieved, samples may be stored for three days in a humidity-controlled chamber.

Oven-dried filter paper, Whatman No. 42, was placed between two identical disc specimens. The two disc samples were $70 \mathrm{~mm}$ in diameter, while the filter paper placed in the middle was $50 \mathrm{~mm}$ in diameter. A seating load of $7 \mathrm{kPa}$ was applied to ensure contact between the filter paper and the soil samples. The whole setup is placed inside a sealed glass jar and stored for 20 days in a box in order to attain moisture equilibration between the filter paper and the disk specimen. The suction corresponding to the moisture content of the sample was obtained from a calibrated chart of the filter paper used in the test (Figure 3). More details about the procedures for calibrating the filter paper are given by AlMahbashi [17].

3.4. Fitting Method. Many curve fitting methods may be considered for the soil suction and water content profile. For this particular research, Fredlund and Xing's [1] method was selected:

$$
\theta_{\mathrm{w}}(\Psi)=\theta_{\mathrm{s}}\left[1-\frac{\ln \left(1+\left(\Psi / h_{\mathrm{r}}\right)\right)}{\ln \left(1+\left(10^{6} / h_{\mathrm{r}}\right)\right)}\right]\left[\frac{1}{\ln \left\{\exp (1)+(\Psi / a)^{n}\right\}^{m}}\right],
$$

where $\Psi$ is the soil suction, $\theta_{\mathrm{w}}$ is the water content, $\theta_{\mathrm{s}}$ is the saturated water content, $\theta_{\mathrm{r}}$ is the residual water content, $a$ is the suction related to the inflection point on the curve, $n$ is the soil parameter related to the slope at the inflection point, $m$ is the soil parameter related to the residual water content, and $h_{\mathrm{r}}$ is the suction related to the volumetric residual water content.

Excellent correlation can be obtained with $R^{2}$ values in excess of 0.95 . The selection of fitting approach is dependent on the evaluation of the researcher.

The AEV and residual suction values have been determined using the graphical method proposed by Vanapalli et al. [4] and represent the points of intersection of tangents to the saturation zone, desaturation zone, and residual zone.

3.5. The Area Concept. While observing many SWCCs and the main control points of the curve, major variations in the area under the curve for different mixtures with different clay contents were noted. The order of variation seems to be related to the first part of the curve, starting from very low suction values up to the inflection point. The trend beyond the inflection point generally converges towards a low moisture zone at high suction levels. This encouraged the researchers to investigate this parameter in order to use it in the prediction of the SWCC for a wide range of clay content. This will certainly reduce the time for design and laboratory 
TABLE 3: Compaction data for variable clay content within mixtures.

\begin{tabular}{lcc}
\hline Proportion of clay within the mixture (\%) & Maximum dry density & Optimum moisture content \\
\hline 5 & 17.5 & 13.5 \\
10 & 17.7 & 15.4 \\
15 & 18.0 & 16.8 \\
30 & 16.5 & 20.0 \\
60 & 14.1 & 25.0 \\
100 & 12.0 & 32.0 \\
\hline
\end{tabular}

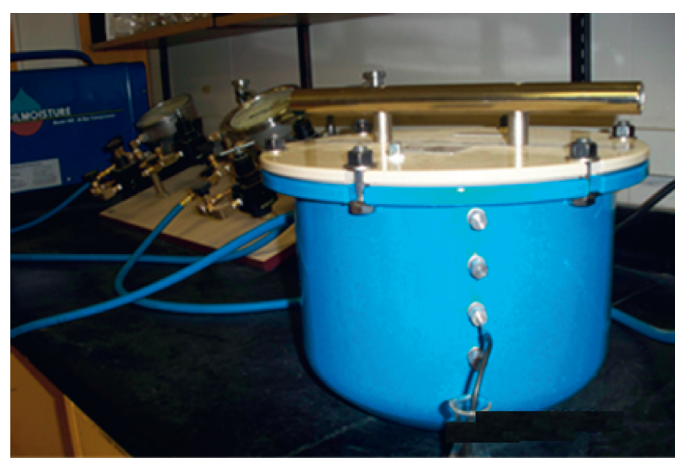

(a)

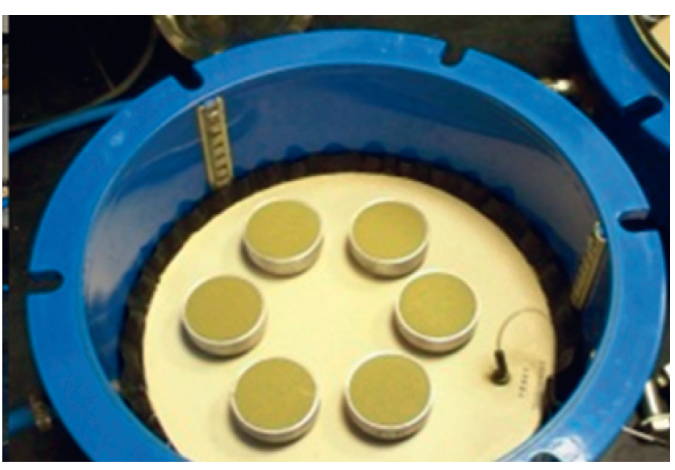

(b)

Figure 2: Pressure plate apparatus.

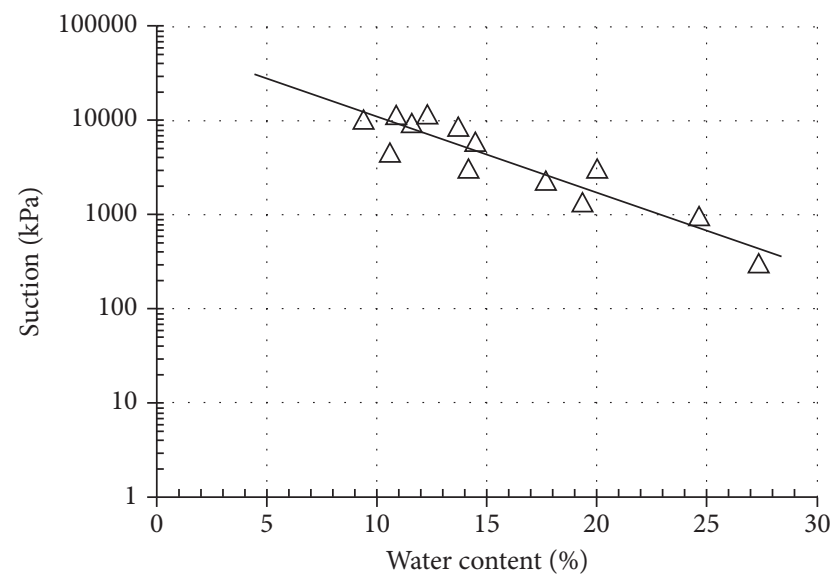

$\triangle$ Calibration points

FIgURE 3: Suction calibration chart for Whatman 42 filter paper.

engineers when dealing with clay-sand liners of variable clay content.

Typical area parameters suggested in this study are shown in Figures 4 and 5 for a sand-bentonite liner and a pure sand material.

The variation in the area below the curve starts well before the AEV and continues up to and beyond the inflection point.

\section{Results and Discussion}

4.1. SWCC Control Points. The SWCC constructed for pure sand and sand with $5 \%, 10 \%, 15 \%, 30 \%$, and $60 \%$ of Al-Qatif

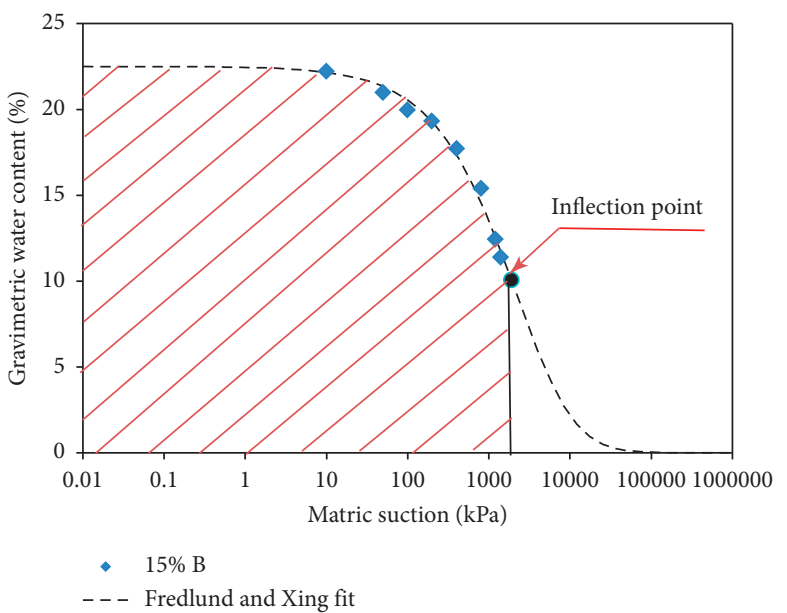

FIgURe 4: Area parameter definition $A_{\mathrm{p}}$ for $15 \%$ bentonite sand clay liner.

clay and other mixtures involving commercial bentonite revealed control points, as presented in Table 4 .

4.2. Saturation Water Content. The clay mineralogy is the most important factor that determines the saturation moisture content in the SWCC plot. Expanding minerals play a significant role in attracting and retaining water, and this is clearly reflected by the increase in saturation moisture content with the increase of clay content. SWCCs are widely spaced for low matric suction, and the spacing is reduced by increasing the matric suction. The curves for all sand-clay 


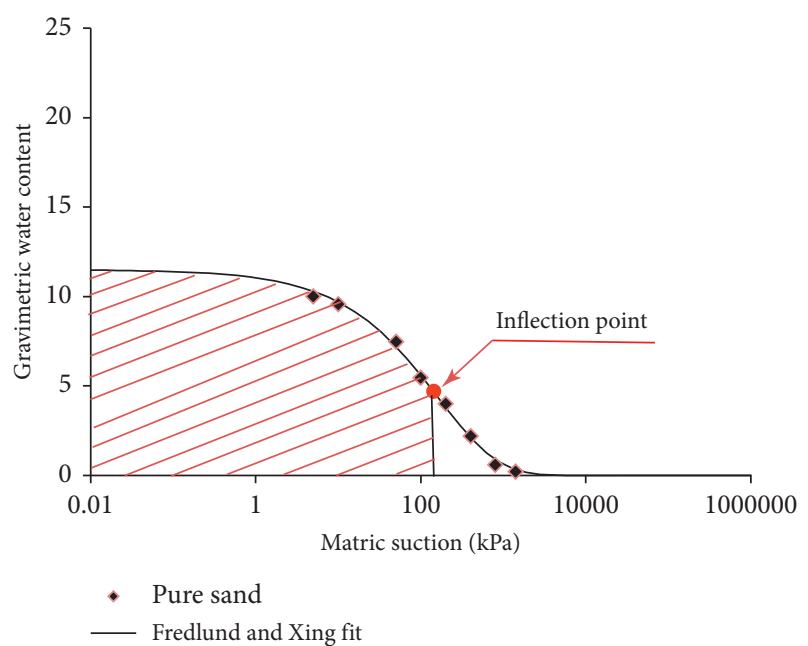

Figure 5: Area parameter $A_{\mathrm{p}}$ for reference pure sand used in the mixture.

mixture profiles converge towards a zone of high matric suction between 10,000 and $100,000 \mathrm{kPa}$ [24].

The saturated water content value is closely related to the porous nature of the mixture and governed by the retention capacity of the clay and proportion of sand. When the clay and fines within the mixture are dominant, a higher degree of saturation is expected. Volume increase and shrinkage are strongly related to the water retention in liners and wastewater barriers made of sand enhanced by clay.

4.3. SWCC Trends for Sand-Clay Mixtures. The SWCC for sand indicated nearly horizontal moisture-suction slope for low suction pressures $(0.1 \mathrm{kPa}$ or less). This is also valid for different selected clay mixtures, but the moisture content is variable. The slope of the SWCC changes gradually when the matric suction is increased until a point of inflection is reached. The slope beyond the inflection point indicates a reversed trend and change of direction. Table 4 presents the $\mathrm{AEV}, R_{\mathrm{s}}$, and $W_{\mathrm{r}}$ based on Fredlund and Xing's [1] fit.

The SWCC of sand-clay mixtures, in general, indicates trend with different control points and slopes. Figures 6-8 present Fredlund and Xing's fit for sand with varying clay content.

4.4. Areas under the Curve. Measurements of the area under the curve can be performed graphically or by computations. The Simpson rule can be utilized if the area is subdivided to many slices of equal width from initially reported suction up to the inflection point. Integrating the function over the same range is found to give reliable results. In this study, one type of sand material is used with different clay contents. Figure 5 shows the contribution of sand alone to the area under the curve. This may be investigated when different types of sand are used with different clay contents. In this part of research, the influence of sand is ignored or assumed to be identical in all tested samples.

The scale of the two axes and dimensions need to be identical when measuring or comparing the area using this procedure. The scale must be semilogarithmic with moisture content in the vertical axis and the matric suction for the horizontal axis. It is suggested to start measuring areas for very low suction $(0.01 \mathrm{kPa})$.

By integrating equation (1), the area under the curve up to the inflection point was calculated and presented for a sample mixture. The first step is to establish the inflection points in order to identify the limits of the required area. Fredlund and Xing's [1] equation is simplified and integrated over the range from $0.01 \mathrm{kPa}$ suction up to the suction value at the inflection point shown as $1,905.46$ for the selected mixture.

The hatched area in Figures 4 and 5 represents the required area under the curve.

$$
\begin{aligned}
& \text { Area }=\int_{\Psi_{1}}^{\Psi_{2}}\left[\theta_{s}\left[1-\frac{\ln \left(1+\left(\Psi / h_{\mathrm{r}}\right)\right)}{\ln \left(1+\left(10^{6} / h_{\mathrm{r}}\right)\right)}\right]\left[\frac{1}{\left[\ln \left\{\exp (1)+(\Psi / a)^{n}\right\}\right]^{m}}\right]\right] \mathrm{d} \Psi \\
& \text { Area }=22.5 \int_{.01}^{1905.46}\left(\left(1-\left(\left(\ln \left(1+\left(\frac{\Psi}{12014.65}\right)\right)\right) \div 4.4335\right)\right) \times\left(1 \div\left(\ln \left(2.71828+\left(\frac{\Psi}{8233.479}\right)^{0.7669}\right)\right)^{7.2059}\right)\right),
\end{aligned}
$$

Area $=27492.126$

The process was repeated for each mixture.

Areas were first obtained for mixtures with clay content as $0 \%, 5 \%, 10 \%, 15 \%, 30 \%, 60 \%$, and $100 \%$. Figure 9 presents a bar diagram for the computed values. For comparison purposes, other clay including bentonite were found not very different from the general trend established for Al-Qatif clay. These are $15 \%$ bentonite, $10 \%$ bentonite with $5 \%$ AlQatif clay, and 5\% bentonite with 10\% Al-Qatif clay. The general SWCC trend was found to be similar to Al-Qatif clay and other mixtures with bentonite. This is due to the similarity in the mineralogy of the two clays [21], although of different origins.

A polynomial trend curve was fitted to relate the area factor to the clay content of the liner.

The shape of the SWCC can be different for clay of different origins, but clay of the same mineralogy is likely to show similar trends with some variation in control points. Elkady et al. [25] showed that the shape of the SWCC of 
TABLE 4: SWCC control points for sand-clay mixtures.

\begin{tabular}{|c|c|c|c|c|c|}
\hline Mixture & $\begin{array}{l}\text { Air-entry value (AEV), } \\
\mathrm{kPa}\end{array}$ & $\begin{array}{c}\text { Residual water content }\left(W_{\mathrm{r}}\right) \text {, } \\
\%\end{array}$ & $\begin{array}{c}\text { Saturated water content }\left(W_{\mathrm{s}}\right) \text {, } \\
\%\end{array}$ & $\begin{array}{l}\text { Residual suction (Rs), } \\
\qquad \mathrm{kPa}\end{array}$ & $R^{2}$ \\
\hline Pure sand & 8.6 & 0.8 & 11.5 & 700 & 0.997 \\
\hline $5 \% \mathrm{Q}$ & 5.0 & 1.3 & 12.0 & 3800 & 0.988 \\
\hline $10 \% \mathrm{Q}$ & 27.0 & 1.4 & 13.0 & 22000 & 0.957 \\
\hline $15 \% \mathrm{Q}$ & 42.0 & 1.4 & 14.5 & 45000 & 0.978 \\
\hline $30 \% \mathrm{Q}$ & 8.6 & 15.3 & 26.0 & 300 & 0.992 \\
\hline $60 \% \mathrm{Q}$ & 11.5 & 22.0 & 35.0 & 700 & 0.988 \\
\hline $100 \% \mathrm{Q}$ & 68.0 & 7.5 & 71.0 & 50000 & 0.991 \\
\hline $5 \% \mathrm{~B}, 10 \% \mathrm{Q}$ & 30.0 & 1.9 & 16.0 & 25000 & 0.978 \\
\hline $10 \% \mathrm{~B}, 5 \% \mathrm{Q}$ & 98.0 & 0.9 & 17.0 & 13000 & 0.973 \\
\hline $15 \% \mathrm{~B}$ & 170.0 & 1.2 & 22.5 & 10000 & 0.988 \\
\hline
\end{tabular}

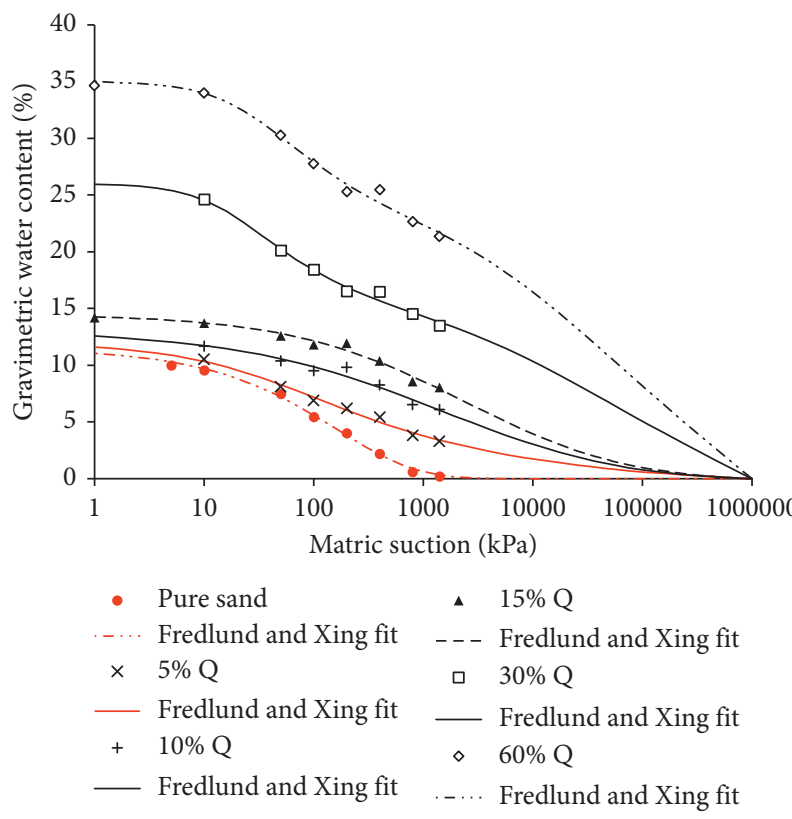

FIGURE 6: SWCC for sand-clay mixtures with clay content of 0,5 , $10,15,30$, and $60 \%$.

sand-clay mixtures transforms from a unimodal form to a bimodal form due to two of pore sizes involved: macropores and micropores. When considering this new concept of shape analysis using areas under the curve, a quantitative evaluation is possible. This is expected to be beneficial for geotechnical designers and laboratory engineers due to the amount of time saved. Areas with similar clay mineralogy can establish a single SWCC chart for different clay additives. This can be repeated or reproduced for other sands commonly used in the liner industry.

Figure 10, with experimental data performed in the laboratory, can be used to establish the zones of different Al-Qatif clay contents for any proposed clay-sand liners. SWCC chart, Figure 11, is constructed to help practicing engineers to use the area under the curve concept. The chart was idealized based on repeated tests and selected clay content. The area function is not linear, and statistical fit indicated a polynomial trend of the second order. Therefore, the shift of the SWCC profile shall not be considered linear and needs to be adjusted following the area under the curve concept. When plotting control points, it is

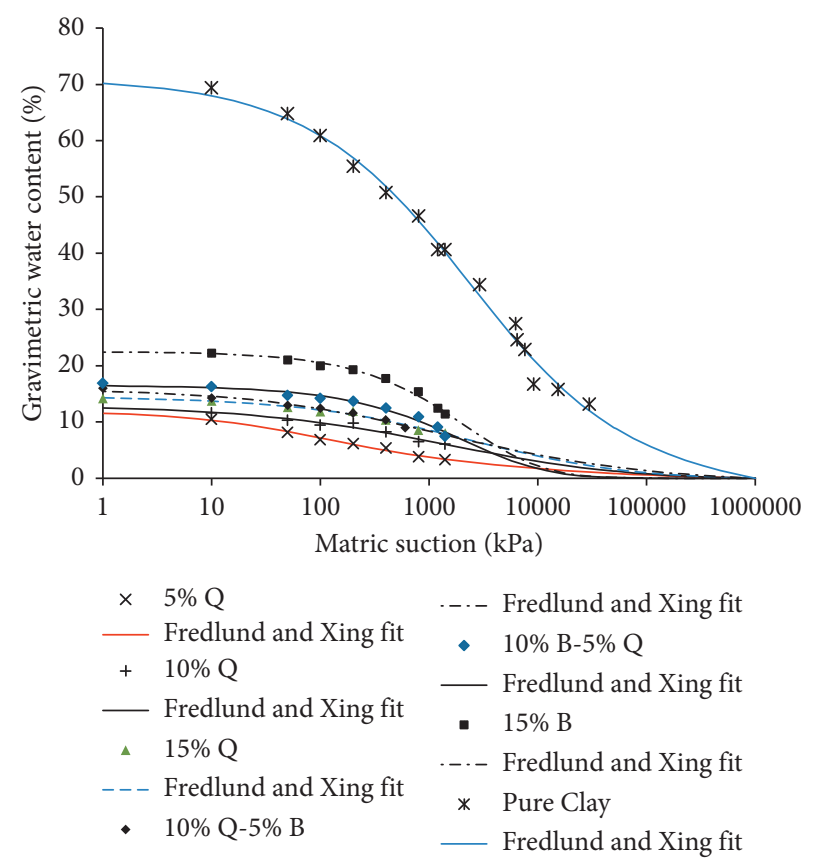

FIgURE 7: SWCC for Al-Qatif pure clay compared with other selected mixtures.

worth noting that the position of the AEV and suction need to be determined by finding the moisture content as correlated to the area factor; similarly, the suction pressure can be obtained from correlations between area factor and suction pressure at $\mathrm{AEV}$. For the residual point, it was observed that it occurs at high suction and is not majorly deviating from the straight lines converging towards $100,000 \mathrm{kPa}$ suction pressure. For the purpose of validation of the prediction chart, the points with $30 \%$ and 60\% Al-Qatif clay are shown in the plot (Figure 12). The SWCC for the pure sand used is indicated in the prediction chart. When the type of sand is altered, a similar prediction chart can be constructed.

When using different types of clay of similar mineralogy in the form of mixtures of local clay and highly plastic bentonite, deviation from the general trend was found to be not serious but depends on the concentration of bentonite used. This can be seen from various plots of the SWCC of 5\% bentonite plus 10\% Al-Qatif clay and 10\% bentonite and 5\% Al-Qatif clay. 


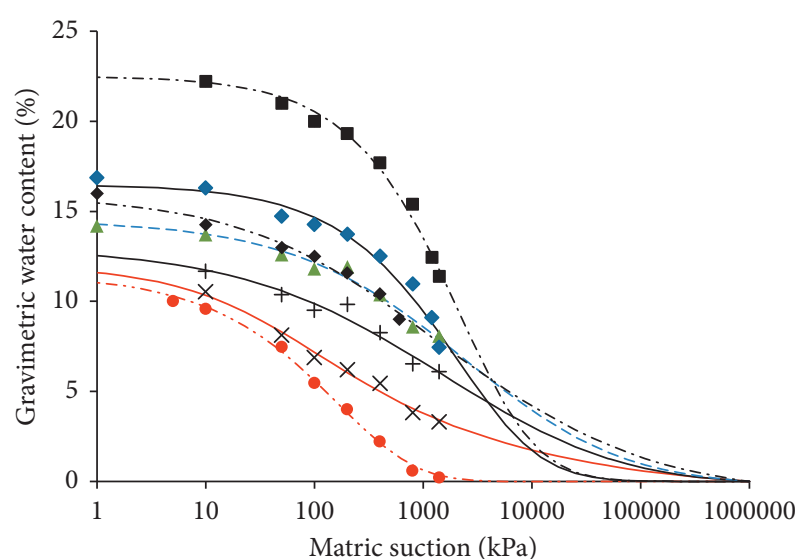

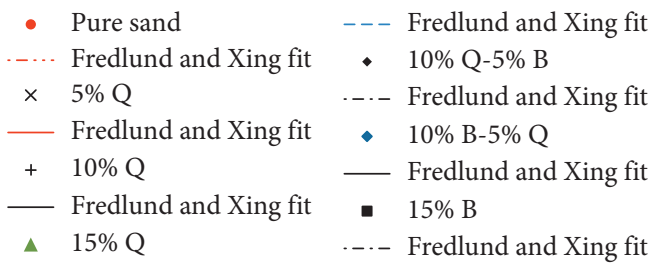

FIGURE 8: SWCC trends of Al-Qatif clay mixtures compared with other mixtures including bentonite clay.

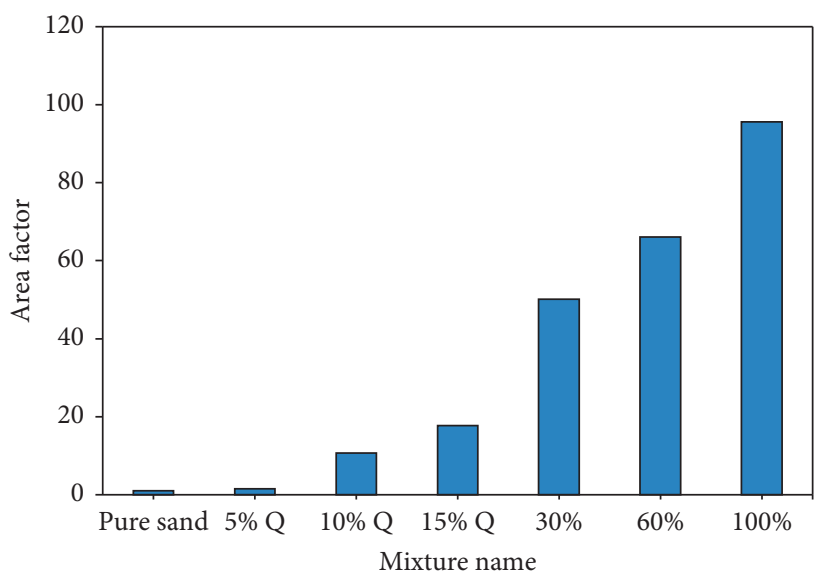

FIgURE 9: Bar diagram for computed values.

Figure 12 presents a comparison between measured and predicted data for mixtures including $15 \%$ and $30 \%$ of Al-Qatif clay. The obtained results fit very well with the proposed area under the curve model. It is worth mentioning that the predicted lines for the SWCC are rather uniform up to mixture containing 20\% of Al-Qatif clay, and beyond this level, the variation is not regular. The upward shift increases with increase of clay content above $20 \%$. The practical range of $\mathrm{Al}$ Qatif clay that is to be used in the liner industry is not expected to go beyond $25 \%$ content. This procedure can be further utilized to compare other clay based on the area under the curve. This can be in the form of a slight shift of the prediction lines and will be of sufficient accuracy for the preliminary design of liner and prediction of geotechnical properties.

Cai et al. [5] discussed different models used in the prediction of the permeability function. They classified these

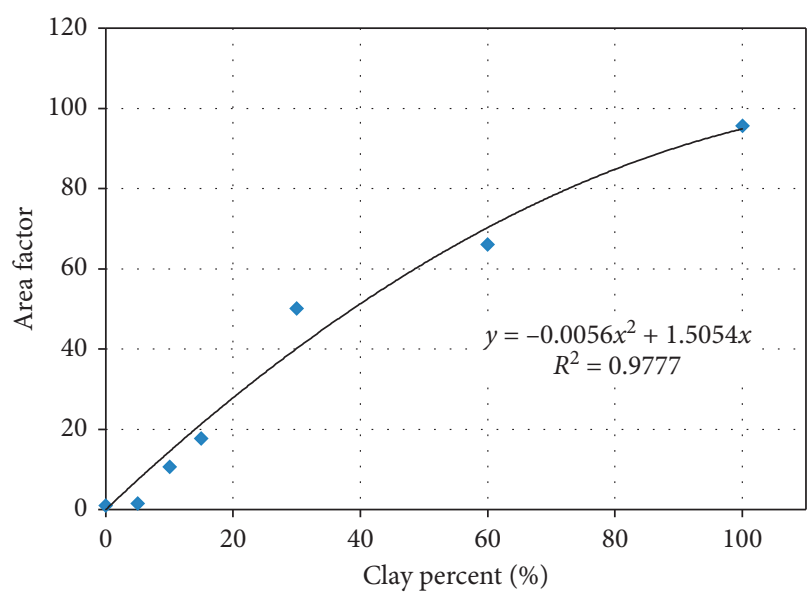

Figure 10: Trend of the area factor at different clay contents excluding $30 \%$ and $60 \%$.

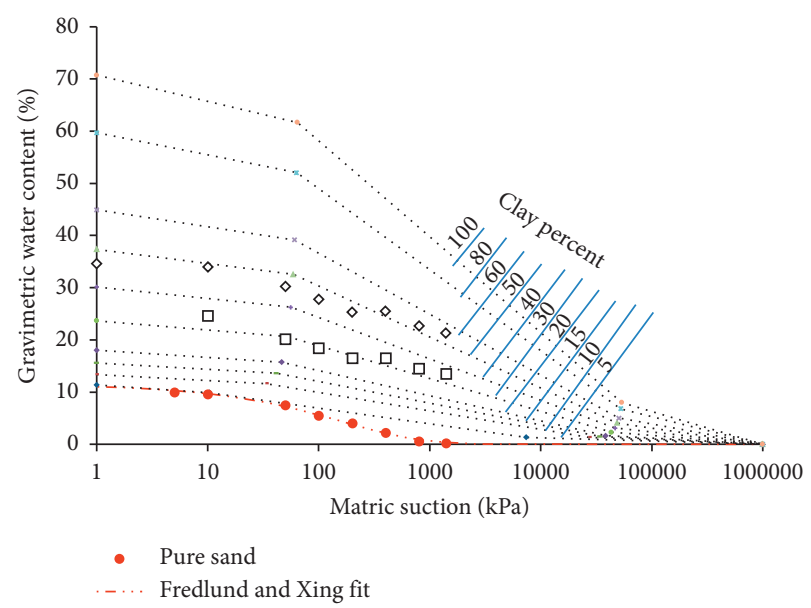

FIGURE 11: Idealized SWCCs for Al-Qatif clay over a range of 0 to $100 \%$.

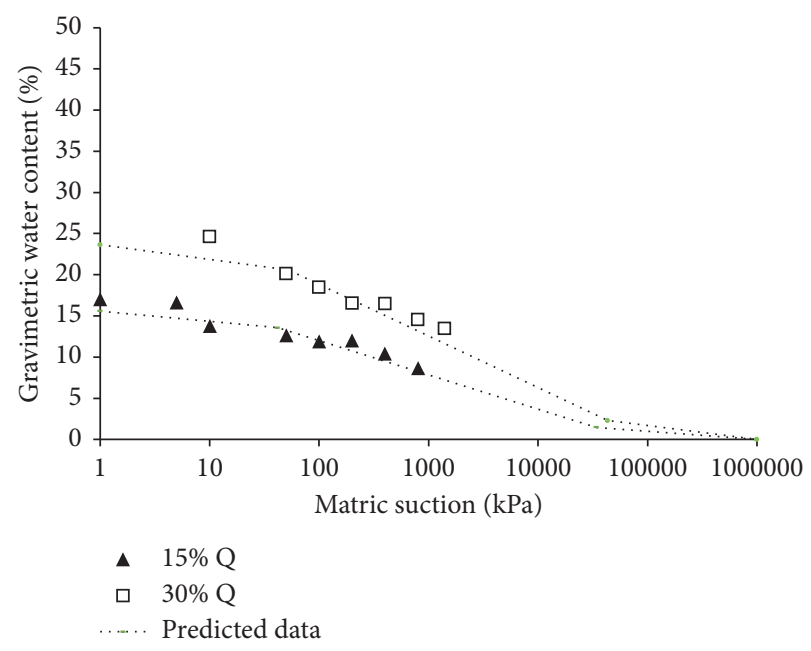

FIGURE 12: Comparison between measured and predicted data.

models into three groups. They are empirical methods, macroscopic models, and statistical models. The theoretical approach conducted by Cai et al. [5] included adding an 
additional density parameter to enable a wide range prediction and not for a single initial dry density. The theoretical approach in this study is limited to the SWCC of a particular soil fitted using Fredlund and Xing's method [1] enhanced with computations of the area under the curve as obtained for variable clay contents. The area under the curve parameter was found to provide a prediction chart with reliable accuracy that can enable successful geotechnical engineers.

\section{Conclusion}

This study considered the use of the area under the curve concept to predict idealized SWCC trends for sand-clay mixtures used in liners. The call for establishing a liner chart for areas of similar mineralogical nature will be useful for design-practicing engineers and laboratory testing agencies. Considerable time will be saved, which will be most welcomed by designers and environmental specialists.

Prediction charts established can form a library for use by designers and research groups in the field of geotechnical and environmental engineering. The SWCC control points were established experimentally for Al-Qatif clay when used with the common fine sand which is used in the construction industry. When using different clay of similar mineralogy or mixtures including local clay and highly plastic bentonite, a deviation from the general trend may be noticed. This deviation was found not significant, and its level depends on the concentration of bentonite used.

\section{Data Availability}

The data used to support the findings of this study are available from the corresponding author upon request.

\section{Conflicts of Interest}

The authors declare that they have no conflicts of interest.

\section{Acknowledgments}

The authors extend their appreciation to the Deanship of Scientific Research at King Saud University for funding this work through the Research Group Program (RG-1440-073).

\section{References}

[1] D. G. Fredlund and A. Xing, "Equations for the soil water characteristic curve," Candian Geotechnical Journal, vol. 31, no. 3, pp. 521-532, 1994.

[2] D. G. Fredlund and H. Rahardjo, Soil Mechanics for Unsaturated Soils, John Wiley \& Sons, New York, NY, USA, 1993.

[3] D. Hillel, Introduction to Soil Physics, Academic Press, New York, NY, USA, 1982.

[4] S. K. Vanapalli, W. S. Sillers, and M. D. Fredlund, "The meaning and relevance of residual state to unsaturated soils," in Proceedings of 51st Canadian Geotechnical Conference, pp. 4-7, Edmonton, Canada, October 1998.

[5] G. Cai, A. Zhou, and D. Sheng, "Permeability function for unsaturated soils with different initial densities," Canadian Geotechnical Journal, vol. 51, no. 12, pp. 1456-1467, 2014.
[6] Al-Mahbashi, M. Ahmed, and M. Dafalla, "Shear strength prediction for an unsaturated sand clay liner," International Journal of Geotechnical Engineering, vol. 2019, pp. 1-11, 2019.

[7] R. H. Brooks and A. T. Corey, "Hydraulic properties of porous media," in Hydrology Paper, vol. 3, Colorado State University, Fort Collins, CO, USA, 1964.

[8] M. T. Van Genuchten, "A closed-form equation for predicting the hydraulic conductivity of unsaturated soils," Soil Science Society of America Journal, vol. 44, no. 5, pp. 892-898, 1980.

[9] H. Q. Pham and D. G. Fredlund, "Equations for the entire soil-water characteristic curve of a volume change soil," Canadian Geotechnical Journal, vol. 45, no. 4, pp. 443-453, 2008.

[10] D. M. Pedroso and D. J. Williams, "A novel approach for modelling soil-water characteristic curves with hysteresis," Computers and Geotechnics, vol. 37, no. 3, pp. 374-380, 2010.

[11] C. A. Burger and C. D. Shackelford, "Soil-water characteristic curves and dual porosity of sand-diatomaceous earth mixtures," Journal of Geotechnical and Geoenvironmental Engineering, vol. 127, no. 9, pp. 790-800, 2001.

[12] X. Chateau and T. B. Viet, "Influence of the temperature on the water content curves: a micromechanical approach," in Unsaturated Soils: Theoretical and Numerical Advances in Unsaturated Soil Mechanics", O. Buzzi, S. Fityus, and D. Sheng, Eds., pp. 849-854, CRC Press, Leiden, Netherlands, 2010.

[13] A.-N. Zhou, D. Sheng, and J. P. Carter, "Modelling the effect of initial density on soil-water characteristic curves," Géotechnique, vol. 62, no. 8, pp. 669-680, 2012.

[14] J. E. C. Montanez, "Suction and volume changes of compacted sand-bentonite mixtures," Imperial College of Science, London, UK, Ph. D. Dissertation, 2002.

[15] S. S. Agus and T. Schanz, "Wetting, drying, suction characteristic curves of bentonite sand," in Proceedings of the Fourth International Conference on Unsaturated Soils, Carefree, AZ, USA, April, 2006.

[16] L. Pei-yong and Y. Qing, "Test study on soil-water characteristic curve of bentonite-sand mixtures," Electronic Journal Geotechnical Engineering, vol. 14, pp. 1-8, 2009.

[17] A. M. Al-Mahbashi, "Soil Water Characteristic Curves of Treated and Untreated Highly Expansive Soil Subjected to Different Stresses," M.Sc. Thesis, KingSaud University, Riyadh, Saudi Arabia, 2014.

[18] A. M. Al-Mahbashi, T. Y. Elkady, and T. O. Alrefeai, "Soil water characteristic curve and improvement in lime treated expansive soil," Geomechanics and Engineering, vol. 8, no. 5, pp. 687-706, 2015.

[19] A. M. Al-Mahbashi, T. Y. Elkady, and M. A. Al-Shamrani, "Hysteresis soil-water characteristic curves of highly expansive clay," European Journal of Environmental and Civil Engineering, vol. 22, no. 9, pp. 1041-1059, 2018.

[20] ASTM D2487, Standard Practice for Classification of Soils for Engineering Purposes (Unified Soil Classification System), ASTM International, West Conshohocken, PA, USA, 2011.

[21] S. Azam, "Influence of mineralogy on swelling and consolidation of soils in eastern Saudi Arabia," Canadian Geotechnical Journal, vol. 40, no. 5, pp. 964-975, 2003.

[22] ASTM D698, Standard Test Methods for Laboratory Compaction Characteristics of Soil Using Standard Effort (12 $400 \mathrm{ft}$ $\left.\mathrm{lbf} / \mathrm{ft}^{3}\right)\left(600 \mathrm{kN} \cdot \mathrm{m} / \mathrm{m}^{3}\right)$, Vol. 15.09, Annual book of ASTM Standards, West Conshohocken, PA, USA, 2002.

[23] ASTM D6836, Standard Test Methods for Determination of the Soil Water Characteristic Curve for Desorption Using a Hanging Column, Pressure Extractor, Chilled Mirror 
Hygrometer, and/or Centrifuge, Vol. 4.08, ASTM International, West Conshohocken, PA, USA, 2002.

[24] M. A. Dafalla and A. Al-Mahbashi, "Effect of adding natural clay on the water retention curve of sand-bentonite mixtures," in Proceedings of 6th International Conference on Unsaturated Soils, Sydney, Australia, July 2014.

[25] T. Y. Elkady, M. A. Dafalla, A. M. Al-Mahbashi, and M. A. Al-Shamrani, "Evaluation of soil water characteristic curves of sand-clay mixtures," International Journal of GEOMATE 4, no. 2, pp. 528-532, 2013. 